\title{
Development of flow-accelerated corrosion prediction method (1) Acquisition of basic experimental data including low temperature condition
}

\author{
Kimitoshi YONEDA*, Ryo MORITA*, Kazutoshi FUJIWARA* and Fumio INADA* \\ ${ }^{*}$ Central Research Institute of Electric Power Industry \\ 1-6-1 Otemachi, Chiyoda-ku, Tokyo 100-8126, Japan \\ E-mail: yone@criepi.denken.or.jp
}

Received 9 April 2015

\begin{abstract}
A series of study is presented to develop a prediction method for pipe wall thinning in power plants in order to improve the maintenance management for piping system. As the first report, experiments for flow-accelerated corrosion (FAC) of carbon steel specimens were conducted and basic data were obtained, focusing on relatively low temperature condition. FAC rate is seen to decrease by lowering temperature and the trend curve tends to remains to keep considerable level in lower temperature around $50{ }^{\circ} \mathrm{C}$. Obtained data would mean that FAC susceptibility of pipeline in condensate demineralizer downstream and deaerator upstream in PWR plants is comparable. In terms of $\mathrm{pH}$, a large drop in FAC rate is seen around $\mathrm{pH} 9.0$ as in previous studies, and its ratio of $\mathrm{pH} 9.2$ to $\mathrm{pH} 7.0$ is approximately $1 / 10$. This ratio fairly agrees with iron solubility in each $\mathrm{pH}$ condition at $150{ }^{\circ} \mathrm{C}$ while it is smaller in lower temperature condition, which may require additional effect related to $\mathrm{pH}$ and temperature to be considered to evaluate the FAC rate. The effect of iron contents on FAC rate is confirmed by referring to saturation solubility of iron. It is suggested that FAC may occur even when the iron concentration in the bulk water is in saturation level, which should be considered in the modelling process for FAC prediction.
\end{abstract}

Key words : Pipe wall thinning, Flow-accelerated corrosion, Thinning rate, Carbon steel, Low temperature

\section{Introduction}

For the stable operation and maintaining integrity of power plants, pipe wall thinning is one of the important issues to be managed. Especially, Flow-Accelerated Corrosion (FAC) requires thorough attention with continuous care for its potential of catastrophic ruptures of large diameter pipes in main piping systems, as seen in Surry (U.S.NRC,1986) and Mihama (NISA, 2004). In Japan, technical management rules for pipe wall thinning have been established based on thinning rate and residual lifetime evaluation relying on pipe wall thickness measurement results, for the use in boiling water reactors (BWR), pressurized water reactors (PWR), and fossil plants (JSME 2006a, 2006b, 2006c).

With wall thickness measurement data, thinning trend at each component can be evaluated, individually. In addition, when more than three measurement data obtained in different outages are available, thinning rate would be calculated with least-square method and the management can be conducted with a certain accuracy and proper conservativeness. However, this may results in enormous number of measurements for each outage in power plants, and in partial, there are some elements evaluated excessively conservative that may be forced to replace much earlier than their essential residual lifetime. On the contrary, there are problems for components whose thickness is hard to be quantified with ordinary measurement tools or in lack of reliable measurement data.

For future improvement of the pipe wall thinning management in Japanese power plants, introduction of prediction method and code for thinning rate and residual lifetime evaluation is expected, while in other countries, several codes or software are already utilized in their plant piping management (Chexal, 1999, Zander, 2003, Persoz, 2006, Tomarov, 2002). Applying such code assured with valid accuracy and reliability, most of the abovementioned problems would be 
solved or more relaxed than before.

The authors have been conducting researches to develop pipe wall thinning prediction method for the use in domestic power plants. At first, fundamental data from original experiments and related numerical simulations are obtained, followed by the equation modelling to predict the thinning rate based on thinning phenomena mechanism. After verifying with experimental and power plant data, the prediction model is finally installed into an in-house prediction software developed for the management in domestic power plants, followed by further improvement and renewals of the model and the software. A series of paper will be presented for each step in this developing process. In this paper, basic experiments for FAC are conducted and FAC rate data is obtained which would be used for verification of the prediction model in the next step.

Many experiments for FAC have been done in the past since the 1970's (Keller, 1974, Berge, 1980, Bignold, 1980 etc.), and the thinning trend by FAC has been revealed against essential parameters, such as temperature, $\mathrm{pH}$, dissolved oxygen, chromium content, fluid velocity, and so on. Through these studies and experiences, susceptible condition for FAC is understood for each parameters and the knowledge is applied practically to power plant operation to prevent or to reduce pipe wall thinning by FAC. In terms of temperature, it is well known that the profile of FAC rate shows a peak around 130 to $150{ }^{\circ} \mathrm{C}$, and decrease towards lower or higher temperature region from the peak.

However, recently, it is pointed out that FAC may considerably occur in relatively low temperature around $50{ }^{\circ} \mathrm{C}$, especially in deoxygenated and neutral water condition for both PWR and BWR plants (Crockett and Horowitz, 2009). In addition, actual FAC rate data with even lower temperature condition of $35{ }^{\circ} \mathrm{C}$ in $\mathrm{BWR}$ condensate line system is shown (Yoneda 2009). Since most of the experimental studies in the past mainly focused on the susceptible temperature condition for FAC (Abe, 2010, Lister, 2011, Utanohara, 2013 etc.), test data obtained with low temperature is scarcely found in publications. Hence, in this study, FAC experiments are conducted including temperature condition lower than $150{ }^{\circ} \mathrm{C}$ and down to $50{ }^{\circ} \mathrm{C}$. The obtained data are related and organized with essential parameters and the trend is analyzed comparing to previous studies.

\section{Experiment}

\subsection{Test loop}

FAC experiments were conducted with an apparatus named "PRINTEMPS" loop, and its schematic is shown in Fig. 1. The apparatus is mainly consisted of low-pressure and low-temperature (LP/LT) loop, and high-pressure and hightemperature (HP/HT) loop. In LP/LT loop, the loop water condition is measured and controlled to maintain water chemical condition for the test. In HP/HT loop, the loop water condition is raised up to the actual plant pipe condition to enhance FAC at the test section. Pure deaerated water is created in the reservoir tank by nitrogen gas bubble purge, and chemical-mixed water is fixed at the chemical tank, where ammonia is mainly contained with certain concentration for PWR condensate condition. The water from three tanks is injected to the HP/HT loop by the injection pump with adjusted mixture. In HP/HT loop, the loop water is driven and circulated by the pump and heated by the dual heaters, and flows through 3 parallel test sections. Each section is equipped with automatic flow rate control valve, which enables to conduct test with three different velocity conditions in one run. A partial of loop water is returned from the HP/HT loop through the heat exchanger and the cooler. After settling at LP/LT condition, water chemical conditions are measured. Measurement items are $\mathrm{pH}$, dissolved oxygen (DO), Redox potential (ORP), and conductivity. The loop water is collected to the drain tank after all the measurements, polished in ion exchange resin, and sent back to the reservoir tank again. All piping and components are made of stainless steel or Teflon tubing, except for the test specimen in the test section.

\subsection{Test section}

The test section is a vertical rectangular flow duct with a cross-section of $20 \mathrm{~mm}$ times $10 \mathrm{~mm}$ and a length of 400 $\mathrm{mm}$, as shown in Fig. 2. The test specimen is a carbon steel round disk with $40 \mathrm{~mm}$ in diameter and $5 \mathrm{~mm}$ in thickness, as shown in Fig. 3, and it is fitted in the height of $250 \mathrm{~mm}$ from the test section inlet. To enhance FAC on the specimen surface, turbulence promoter can be installed in the specimen upstream to create flow contraction. In this situation, test specimen with a cut in the upstream side is used to fit in with the turbulence promoter to the test section. The contraction height of the turbulence promoter $(\mathrm{h})$ can be changed up to $3 \mathrm{~mm}$ i.e. contraction area ratio of 0.7 . In front of the test section, observation window made of Pyrex glass is set to visualize the specimen surface and to enable optical measurement of the thinning amount. 


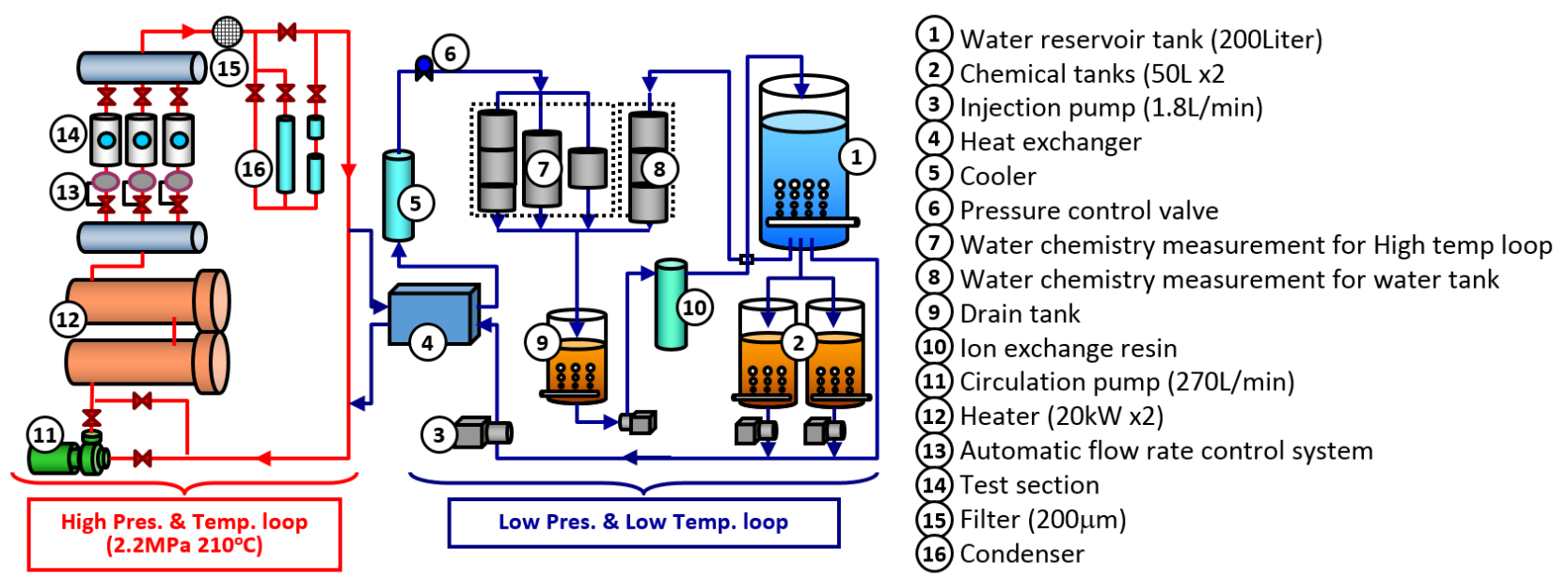

Fig. 1 Schematic of the experimental apparatus "PRINTEMPS"
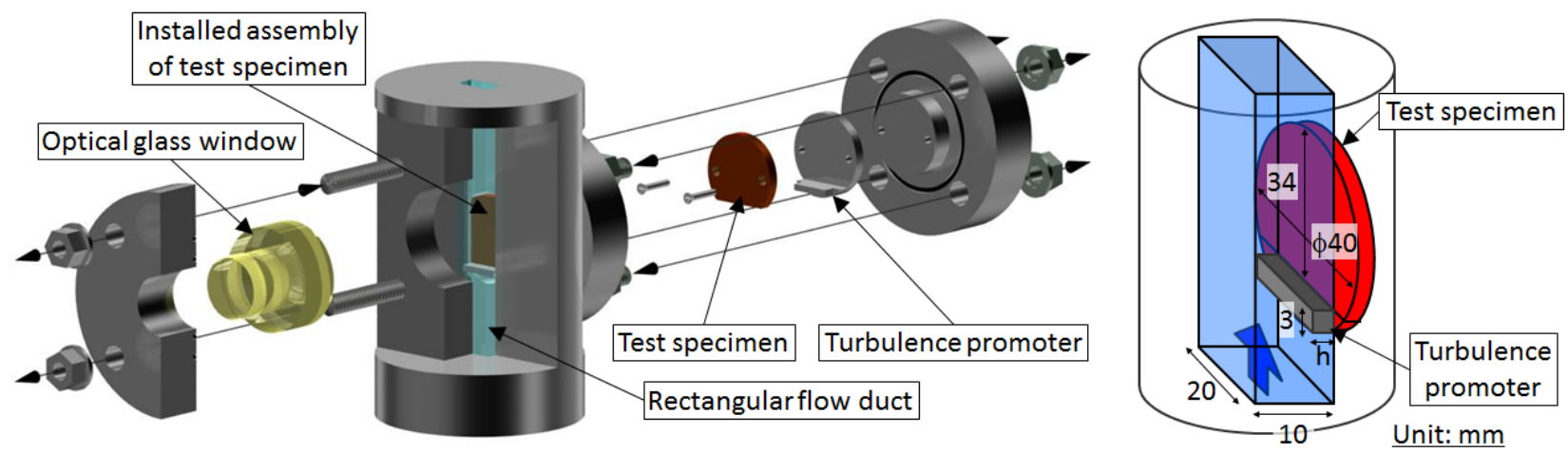

Fig. 2 Schematic of the test section

(Left: Decomposed view, Right: Dimensions around test specimen)

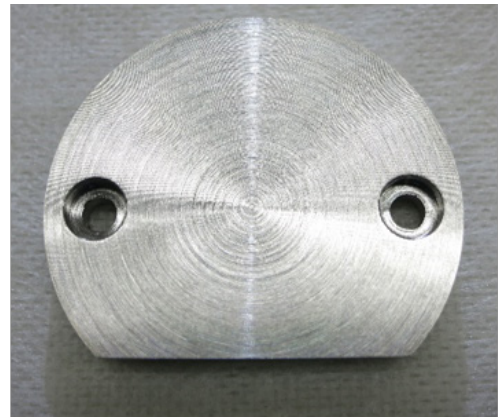

(a) Test specimen for contraction

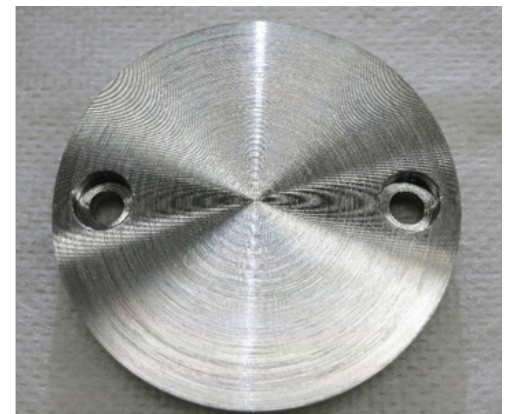

(b) Test specimen for no contraction

Fig. 3 Photos of test specimen

\subsection{Test condition}

The test loop condition of the experiment is listed in Table 1. The main parameter is $\mathrm{pH}$, temperature, velocity and contraction height. Ammonia is injected for alkaline $\mathrm{pH}$ control, and no additives for neutral $\mathrm{pH}$. Half of the tests is focused on low temperature condition from 50 to $150{ }^{\circ} \mathrm{C}$ with neutral $\mathrm{pH}$, and the other half for $\mathrm{pH}$ effect with constant temperature at $150{ }^{\circ} \mathrm{C}$. For each test specimen (TS), mean velocity (V) and contraction height conditions are set individually. DO is kept below $1.0 \mathrm{ppb}$ with continuous nitrogen gas purge into reservoir tank. ORP is not set as an aimed value, however, the loop water is maintained in a reducing condition. Duration time of the tests is not set constant since the decision for terminating each run depends on the confirmation of FAC trend of the specimens which differs between test loop condition or some irregular events which may force loop shut-down. As a result, most of the tests are conducted 
around 3 to 4 weeks.

Test specimens for the test are all manufactured from the same carbon steel plate. Its chemical composition is shown in Table 2. Chromium content, the most important material parameter for FAC, for the specimen is $0.001 \mathrm{wt} \% \mathrm{which}$ is very low level in terms of FAC inhibition according to previous studies (Horowitz 2003, Trevin 2005).

Table 1 Matrix of the test loop condition

\begin{tabular}{|c|c|c|c|c|c|c|c|c|}
\hline \multirow{2}{*}{$\begin{array}{l}\text { Test } \\
\text { run }\end{array}$} & \multirow{2}{*}{$\begin{array}{c}\text { Temperature } \\
{\left[{ }^{\circ} \mathrm{C}\right]}\end{array}$} & \multirow{2}{*}{$\begin{array}{c}\mathrm{pH}_{25^{\circ} \mathrm{C}} \\
{[-]}\end{array}$} & \multicolumn{3}{|c|}{ Velocity (V) [m/s], Contraction height (h) $[\mathrm{mm}]$} & \multirow{2}{*}{$\begin{array}{c}\mathrm{DO} \\
{[\mathrm{ppb}]}\end{array}$} & \multirow{2}{*}{$\begin{array}{l}\text { ORP } \\
{[\mathrm{mV}]}\end{array}$} & \multirow{2}{*}{$\begin{array}{c}\text { Duration } \\
\text { [hours] }\end{array}$} \\
\hline & & & TS-1 & TS-2 & TS-3 & & & \\
\hline$\# 01$ & 50 & 7.0 & $4.5 \mathrm{~m} / \mathrm{s}, 3 \mathrm{~mm}$ & $4.5 \mathrm{~m} / \mathrm{s}, 0 \mathrm{~mm}$ & $10 \mathrm{~m} / \mathrm{s}, 0 \mathrm{~mm}$ & \multirow{12}{*}{$<1.0$} & \multirow{12}{*}{$\begin{array}{c}-200 \\
\sim \\
-500\end{array}$} & 690 \\
\hline$\# 02$ & 80 & 7.0 & $4.5 \mathrm{~m} / \mathrm{s}, 3 \mathrm{~mm}$ & $4.5 \mathrm{~m} / \mathrm{s}, 0 \mathrm{~mm}$ & $(\mathrm{~N} / \mathrm{A})$ & & & 500 \\
\hline$\# 03$ & 100 & 7.0 & $4.5 \mathrm{~m} / \mathrm{s}, 3 \mathrm{~mm}$ & $4.5 \mathrm{~m} / \mathrm{s}, 0 \mathrm{~mm}$ & $10 \mathrm{~m} / \mathrm{s}, 0 \mathrm{~mm}$ & & & 530 \\
\hline$\# 04$ & 120 & 7.0 & $4.5 \mathrm{~m} / \mathrm{s}, 3 \mathrm{~mm}$ & $4.5 \mathrm{~m} / \mathrm{s}, 0 \mathrm{~mm}$ & $(\mathrm{~N} / \mathrm{A})$ & & & 380 \\
\hline$\# 05$ & 150 & 7.0 & $4.5 \mathrm{~m} / \mathrm{s}, 3 \mathrm{~mm}$ & $4.5 \mathrm{~m} / \mathrm{s}, 0 \mathrm{~mm}$ & $10 \mathrm{~m} / \mathrm{s}, 0 \mathrm{~mm}$ & & & 540 \\
\hline$\# 06$ & 150 & 8.8 & $4.5 \mathrm{~m} / \mathrm{s}, 3 \mathrm{~mm}$ & $4.5 \mathrm{~m} / \mathrm{s}, 0 \mathrm{~mm}$ & $10 \mathrm{~m} / \mathrm{s}, 0 \mathrm{~mm}$ & & & 240 \\
\hline$\# 07$ & 150 & 8.9 & $4.5 \mathrm{~m} / \mathrm{s}, 3 \mathrm{~mm}$ & $3.0 \mathrm{~m} / \mathrm{s}, 3 \mathrm{~mm}$ & $1.5 \mathrm{~m} / \mathrm{s}, 3 \mathrm{~mm}$ & & & 600 \\
\hline$\# 08$ & 150 & 9.0 & $4.5 \mathrm{~m} / \mathrm{s}, 3 \mathrm{~mm}$ & $4.5 \mathrm{~m} / \mathrm{s}, 2 \mathrm{~mm}$ & $4.5 \mathrm{~m} / \mathrm{s}, 1 \mathrm{~mm}$ & & & 820 \\
\hline$\# 09$ & 150 & 9.2 & $4.5 \mathrm{~m} / \mathrm{s}, 3 \mathrm{~mm}$ & $4.5 \mathrm{~m} / \mathrm{s}, 0 \mathrm{~mm}$ & $10 \mathrm{~m} / \mathrm{s}, 0 \mathrm{~mm}$ & & & 600 \\
\hline$\# 10$ & 150 & 9.4 & $4.5 \mathrm{~m} / \mathrm{s}, 3 \mathrm{~mm}$ & $3.0 \mathrm{~m} / \mathrm{s}, 3 \mathrm{~mm}$ & $1.5 \mathrm{~m} / \mathrm{s}, 3 \mathrm{~mm}$ & & & 580 \\
\hline$\# 11$ & 150 & 9.8 & $4.5 \mathrm{~m} / \mathrm{s}, 3 \mathrm{~mm}$ & $3.0 \mathrm{~m} / \mathrm{s}, 3 \mathrm{~mm}$ & $6.0 \mathrm{~m} / \mathrm{s}, 3 \mathrm{~mm}$ & & & 450 \\
\hline$\# 12$ & 50 & 9.2 & $4.5 \mathrm{~m} / \mathrm{s}, 3 \mathrm{~mm}$ & $4.5 \mathrm{~m} / \mathrm{s}, 0 \mathrm{~mm}$ & (N/A) & & & 630 \\
\hline
\end{tabular}

Table 2 Chemical composition of the test specimen material (wt\%)

\begin{tabular}{|c|c|c|c|c|c|c|}
\hline \multicolumn{7}{|c|}{ Carbon steel JIS STPT480 } \\
\hline $\mathrm{C}$ & $\mathrm{Si}$ & $\mathrm{Mn}$ & $\mathrm{P}$ & $\mathrm{S}$ & $\mathrm{Cr}$ & Mo \\
\hline 0.25 & 0.24 & 0.80 & 0.017 & 0.010 & 0.001 & $<0.01$ \\
\hline
\end{tabular}

\subsection{Thinning measurements}

Thinning amount of the test specimen is measured with two methods in this experiment; in-situ measurement and post-test measurement, either of them applying optical LASER technique.

For the in-situ measurement, displacement sensors (KEYENCE LK-G150) is used. In front of each test section, the sensors are mounted on a 3-axis automatic stage assembly (SIGMA KOKI SGSP20-35) and the test specimen surface is scanned along a programmed routine lines periodically through the observation window. Scanning area is limited within a small area on the specimen center, $4 \mathrm{~mm}$ in width and $10 \mathrm{~mm}$ in height. Periodic scanning is conducted with 12 hours interval, and each scanning includes 5 repeats to improve measurement accuracy by calculating the average values for the area.

For the post-test measurement, 3D geometry measurement system (KEYENCE KS-1100) is used. The whole specimen surface is scanned optically after the test, and compared with the initial status scanned before the test.

\section{Results and discussions}

\subsection{Surface observation}

After a certain duration time, the test specimen is taken out from the test section. Some photo samples of post-test specimen are shown in Fig. 4, all with the same velocity and flow contraction conditions. Compared to the pre-test status shown in Fig.3, among the specimen surface, the area exposed to water in the flow duct is seen to be corroded by FAC. For the tests in susceptible condition such as neutral $\mathrm{pH}$ or temperature at $150{ }^{\circ} \mathrm{C}$, considerable effect is observed on the exposed surface. For the test in alkaline $\mathrm{pH}$ with low temperature condition, thinning is not comparably enhanced as the grinded line of manufacturing is still remained. 


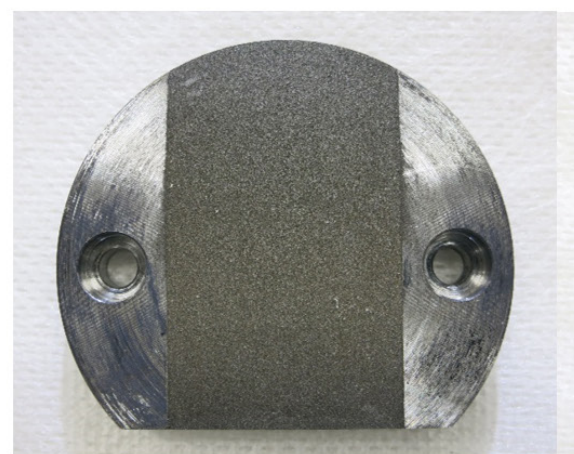

(a) $\mathrm{pH7.0,} \mathrm{T}=50^{\circ} \mathrm{C}$

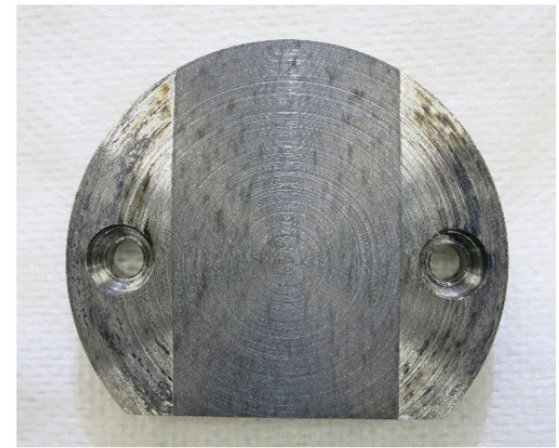

(d) $\mathrm{pH} 9.2, \mathrm{~T}=50^{\circ} \mathrm{C}$

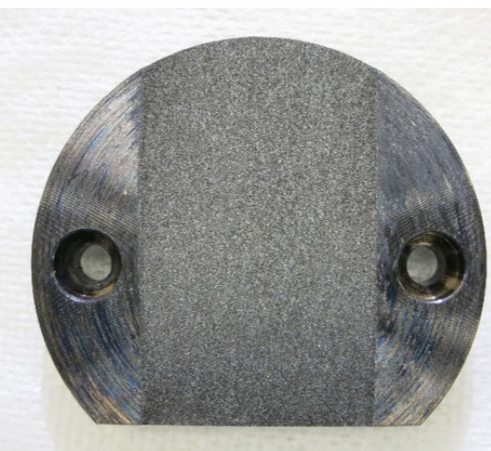

(b) $\mathrm{pH7.0,T}=100^{\circ} \mathrm{C}$

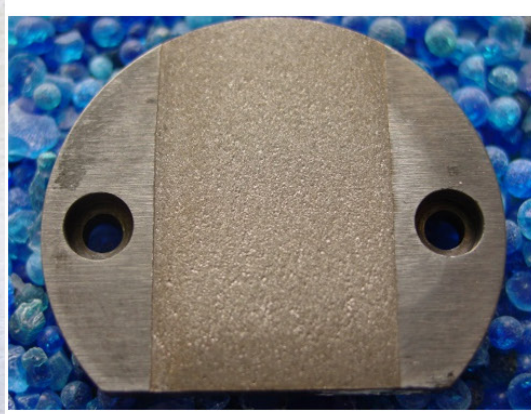

(e) $\mathrm{pH} 9.0, \mathrm{~T}=150^{\circ} \mathrm{C}$

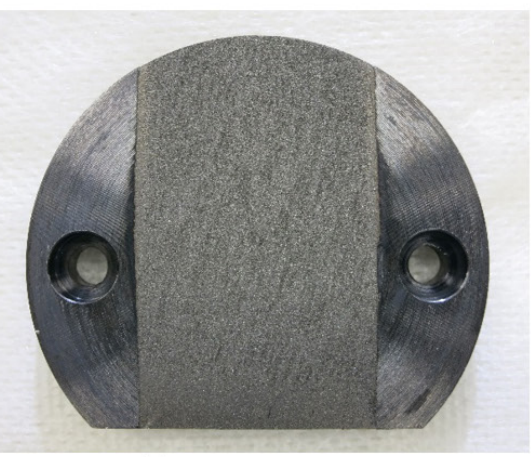

(c) $\mathrm{pH} 7.0, \mathrm{~T}=150^{\circ} \mathrm{C}$

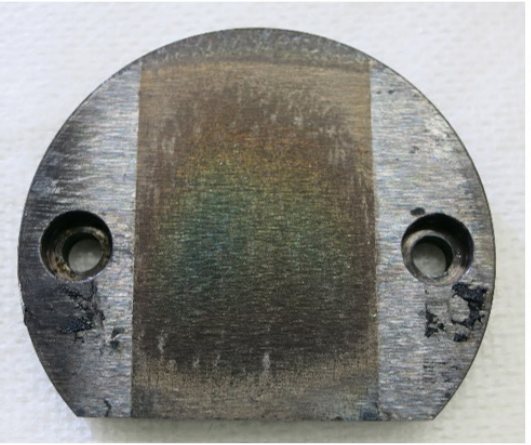

(f) $\mathrm{pH} 9.8, \mathrm{~T}=150^{\circ} \mathrm{C}$

Fig. 4 Photos of post-test specimen surface (conditions with $V=4.5 \mathrm{~m} / \mathrm{s}, \mathrm{h}=3 \mathrm{~mm}$ )

\subsection{FAC rate}

\subsubsection{In-situ measurement results}

From the in-situ measurements with laser displacement sensor, thinning propagation and FAC rate are evaluated. An example of scanning data set is shown in Fig. 5. As described in chapter 2.4, small limited area in the specimen center is scanned periodically and difference in depth is seen between the data obtained with intervals of about 10 days. Average values for these 2-dimensional scanned data are calculated to evaluate FAC rate. Some examples are shown in the timeseries plots in Fig.6. As a trend for each run, nearly constant thinning amount increase can be seen with time, and the FAC rate is estimated by linear approximation. Values of FAC rate are comparable with those estimated by post-test scanning shown afterwards in Fig.9(a), however, considerable scattering is seen for each plot. Consequently, this in-situ measurement results are referred only for relatively large FAC rate cases.

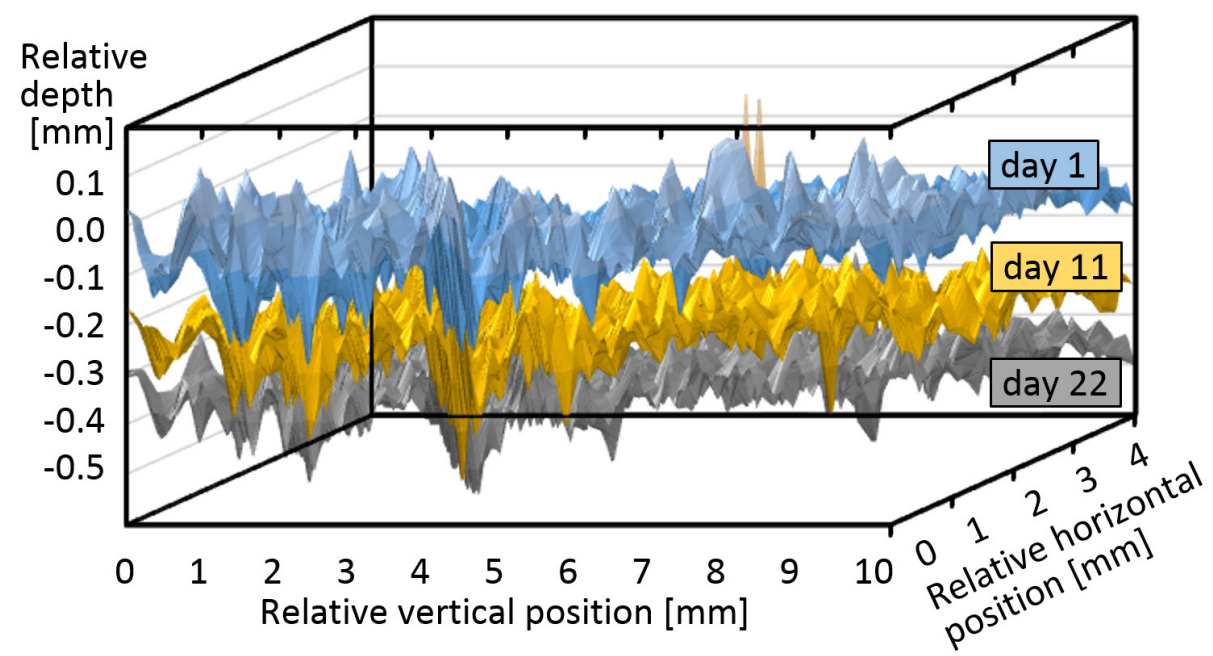

Fig. 5 Example of in-situ scanning measurement data (Run \#05 TS-3) 


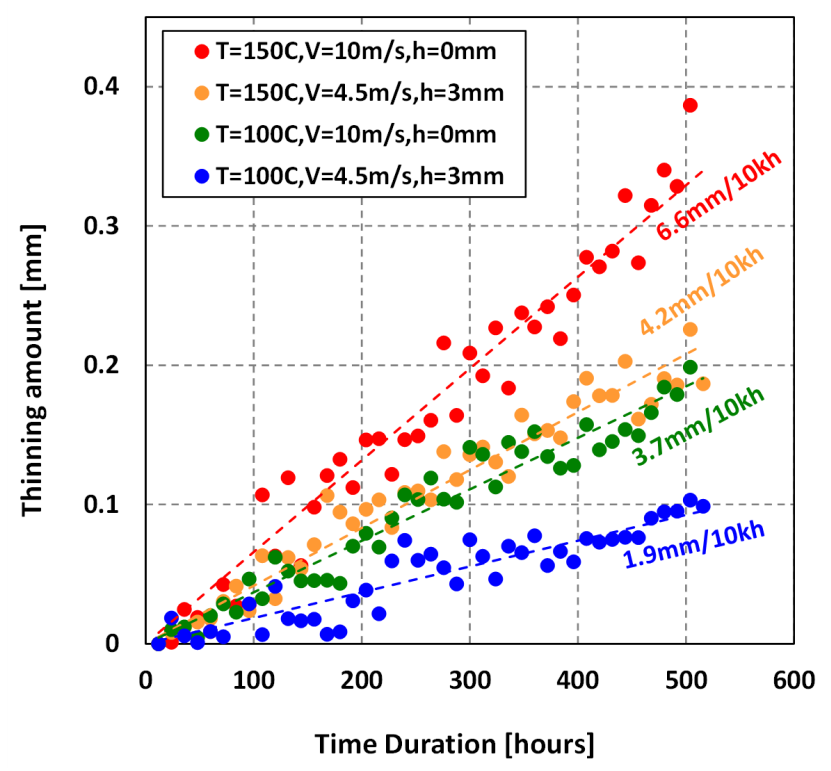

Fig. 6 Thinning trend obtained by in-situ scanning measurement (pH7.0)

\subsubsection{Post-test scanning results}

Post-test scanning is conducted for all test specimens to evaluate thinning amount compared with the initial state. An example of the scanned data for the whole surface of a specimen is shown in Fig. 7. Considerable thinning can be seen in the central region exposed to the flow path while the regions aside remained with initial thickness. With flow contraction, maximum thinning region is seen in some distance from the upstream edge, and the thinning amount is gradually decreased towards the downstream.

To compare the results in terms of major parameters, thinning data profile on the vertical center line is extracted for each test condition and converted to FAC rate by simply dividing by duration time. In Fig. 8, effects of temperature, pH, velocity, and contraction height are shown, respectively. As well-known from previous studies, FAC rate increase can be seen with temperature rise from low temperature condition to $150{ }^{\circ} \mathrm{C}$, with $\mathrm{pH}$ decrease from alkaline to neutral condition, and with velocity increase. For the test conditions with flow contraction height of $3 \mathrm{~mm}$, shown in Fig. 8 (a), (b) and (c), the profiles are almost resembled as they have a peak around $10 \mathrm{~mm}$ from the upstream edge. This is due to the turbulence and recirculation flow created in the contraction downstream, as seen in downstream of orifice installed in pipelines (Bignold, 1980, NISA, 2004, Makino, 2006, Utanohara, 2012 etc.). When the contraction height is lowered, the peak position is shifted towards the upstream edge as shown in Fig. 8(d).

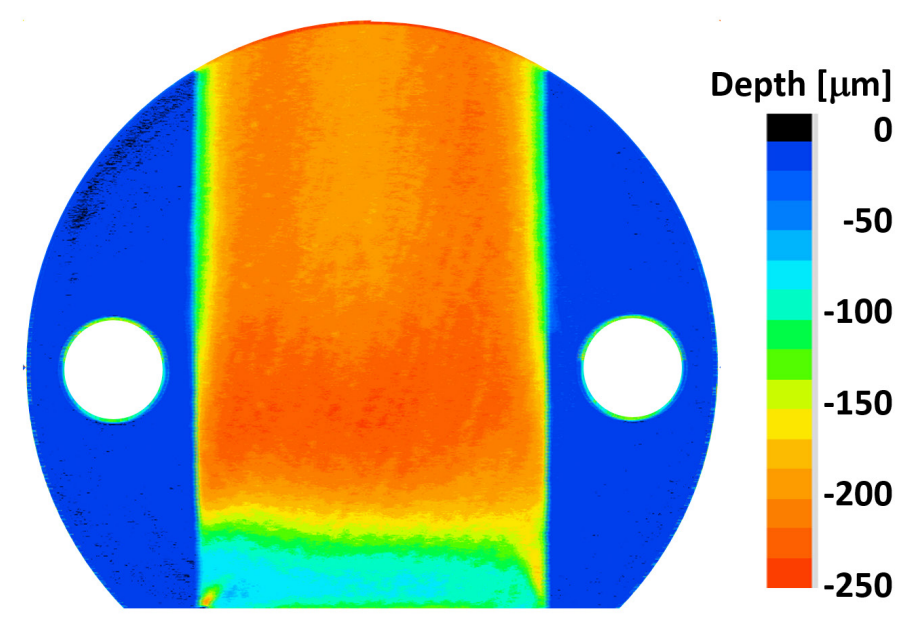

Fig. 7 Example of post-test scanning for the whole specimen surface (Run \#05 TS-1) 

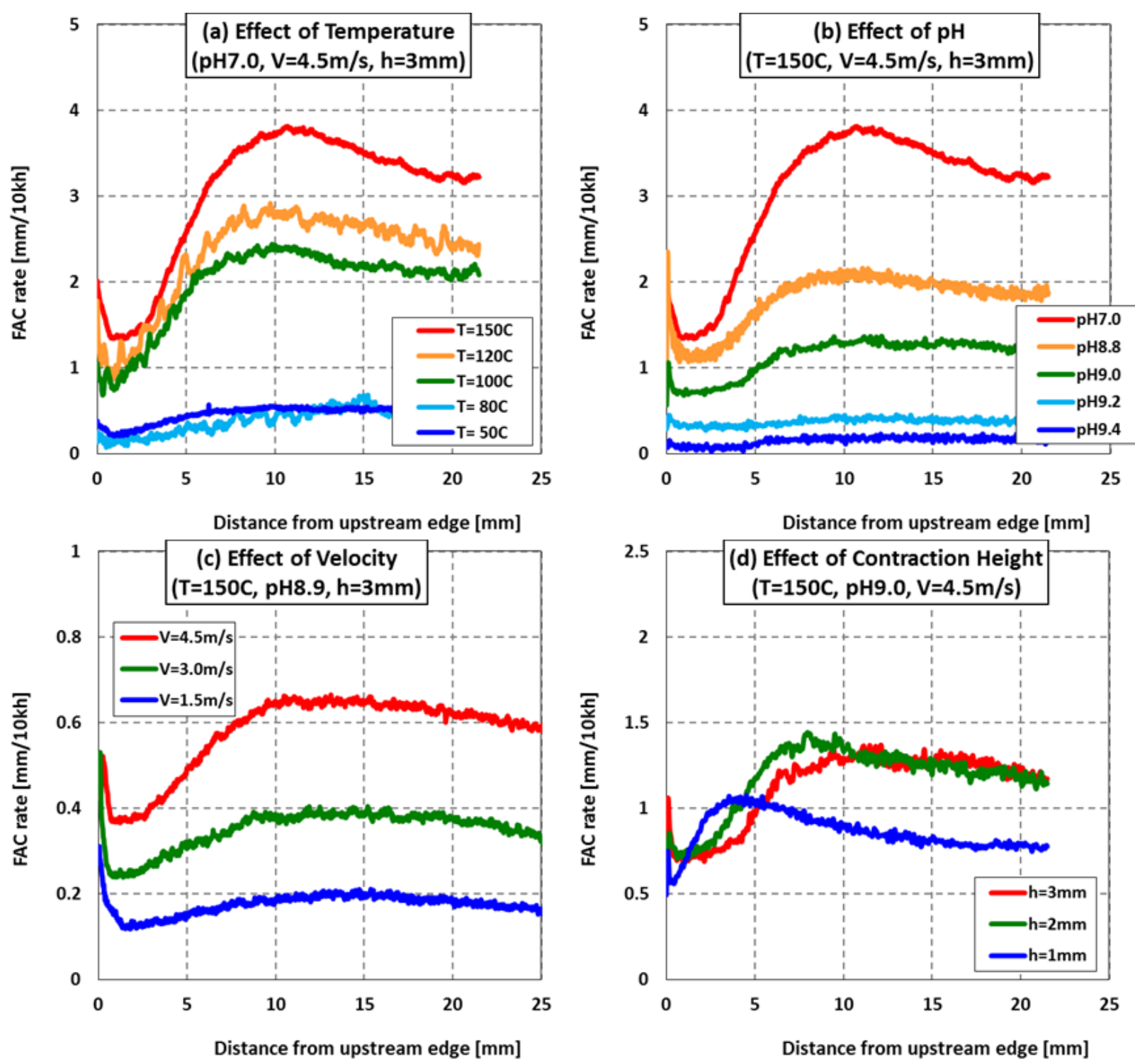

Fig. 8 FAC rate profiles in streamwise direction

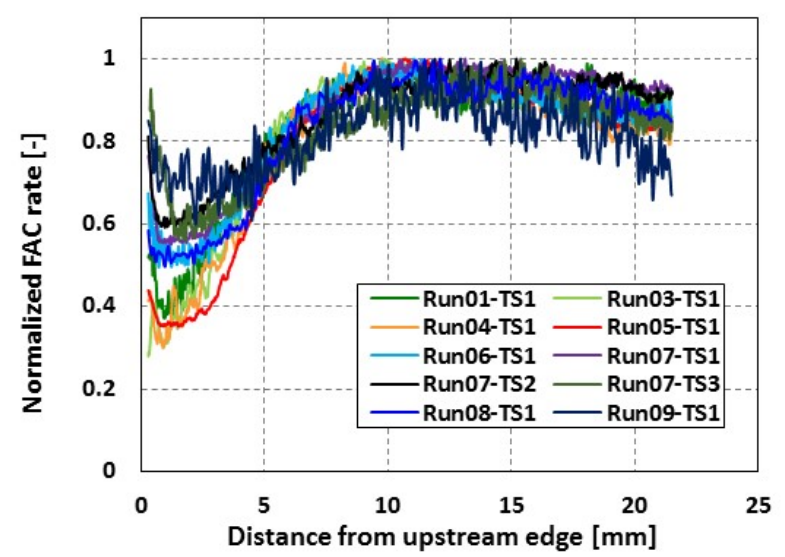

Fig. 9 Normalized FAC rate profiles for $h=3 \mathrm{~mm}$ contraction cases

In the following section, averaged FAC rate values are compared. The average values are calculated based on the certain section from the streamwise profile plotted in Fig. 8, i.e. region of 5 to $20 \mathrm{~mm}$ from upstream edge. This region was selected since, for $3 \mathrm{~mm}$ contraction height case, it represents the common profile including the peak at 10 to $15 \mathrm{~mm}$ from upstream edge for most of the cases as shown in Fig. 9, and for no contraction case, it may exclude small disturbance 
effect of specimen upstream edge.

\subsubsection{Average data in terms of major parameters}

Present FAC rate data in terms of temperature is shown in Fig. 10(a). FAC rate is seen to decrease from $150{ }^{\circ} \mathrm{C}$ to lower condition, and the ratio of the $\mathrm{FAC}$ rate at $50{ }^{\circ} \mathrm{C}$ to $150{ }^{\circ} \mathrm{C}$ is approximately $1 / 7$ to $1 / 6$. However, the trend curve is not approaching towards negligible rate in low temperature condition, and instead remains to keep considerable level which may require attention. For instance, FAC rate for $50^{\circ} \mathrm{C}$ with $\mathrm{pH} 7.0$ is nearly the same or rather larger than that of $150{ }^{\circ} \mathrm{C}$ with $\mathrm{pH}$ 9.2. This would mean that in PWR plant pipeline, FAC susceptibility in condensate demineralizer downstream with temperature around 30 to $50{ }^{\circ} \mathrm{C}$ and neutral $\mathrm{pH}$ at before $\mathrm{pH}$ agent injection point, where wall thickness inspection was not recommended or required in the past (EPRI, 1999, Yamakami, 2008), and deaerator upstream with temperature around 140 to $150^{\circ} \mathrm{C}$ and alkaline $\mathrm{pH}$ about 9.2 in normal AVT (All Volatile Treatment) condition, known to have large potential of catastrophic pipe rupture (NISA, 2004), is comparable.

To confirm the availability of FAC rate data in low temperature region obtained in the past, and to compare qualitative trend in terms of temperature, present data is plotted with those of previous studies (Bignold, 1980, Heitmann, 1982 , Tsuruta, 2006, Fujiwara, 2010) in Fig. 10(b). As mentioned in the introduction, not much data is obtained so far and no previous data was found to extend down to $50{ }^{\circ} \mathrm{C}$ besides the present. At least, FAC rate decrease from temperature about $120^{\circ} \mathrm{C}$ down to about $80^{\circ} \mathrm{C}$ seems to be a common qualitative trend for all of the data. And for temperature region below $80{ }^{\circ} \mathrm{C}$, some data keep decreasing while the others, including the present, do not decrease. Further extension of data acquisition in low temperature region is required to confirm overall trend.
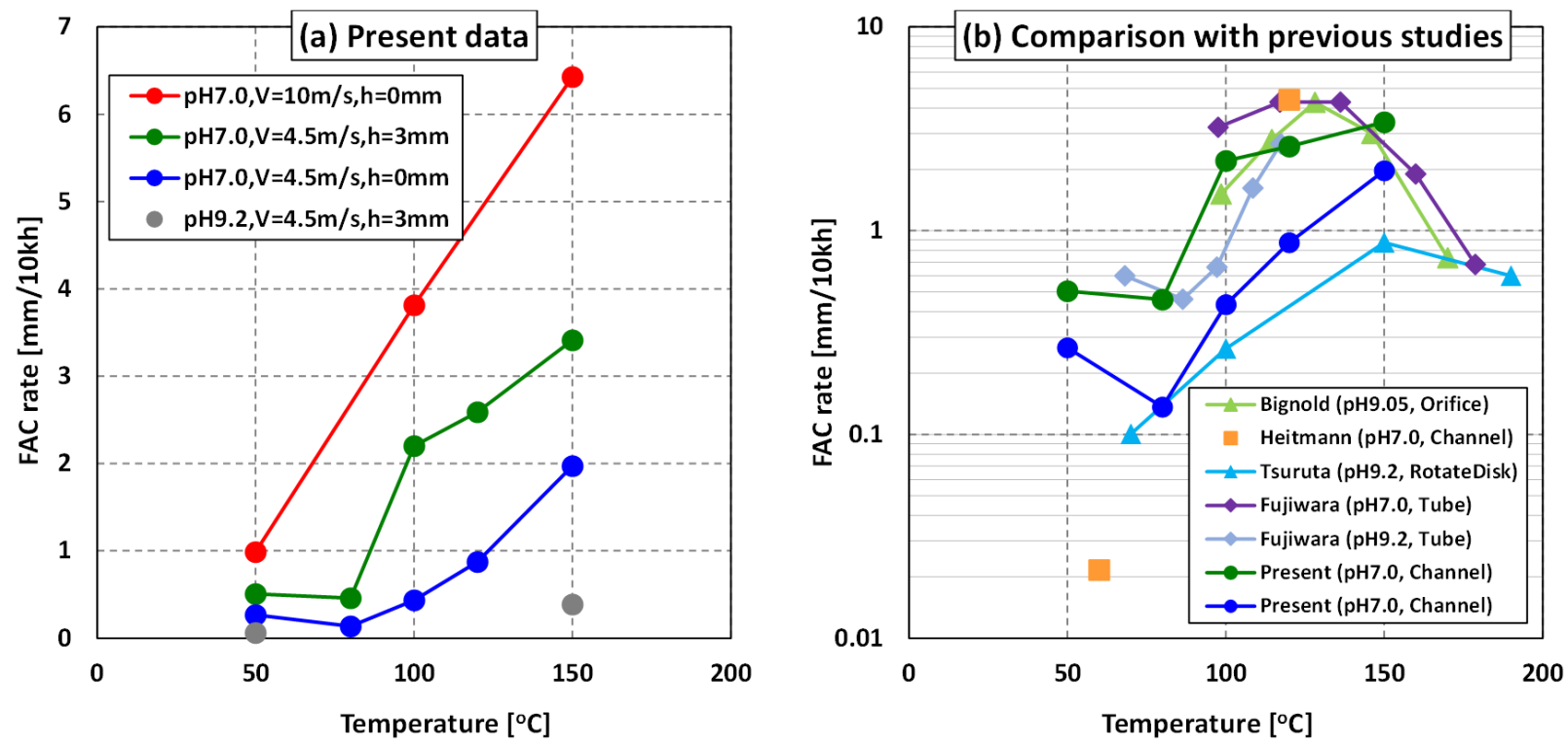

Fig. 10 Average FAC rate trend in terms of temperature

Present FAC rate data in terms of $\mathrm{pH}$ is shown in Fig. 11(a), and a large drop is seen around pH 9.0. In Fig. 11(b), data are converted to relative values based on neutral $\mathrm{pH}$ data, and plotted with data from previous studies (Abe, 2010, Kastner, 1990). Most of the data are seen to show almost similar behavior in the region from neutral $\mathrm{pH}$ to alkaline $\mathrm{pH}$ of about 9.5, and the ratio of the FAC rate at $\mathrm{pH} 9.2$ to $\mathrm{pH} 7.0$ is approximately $1 / 10$. 

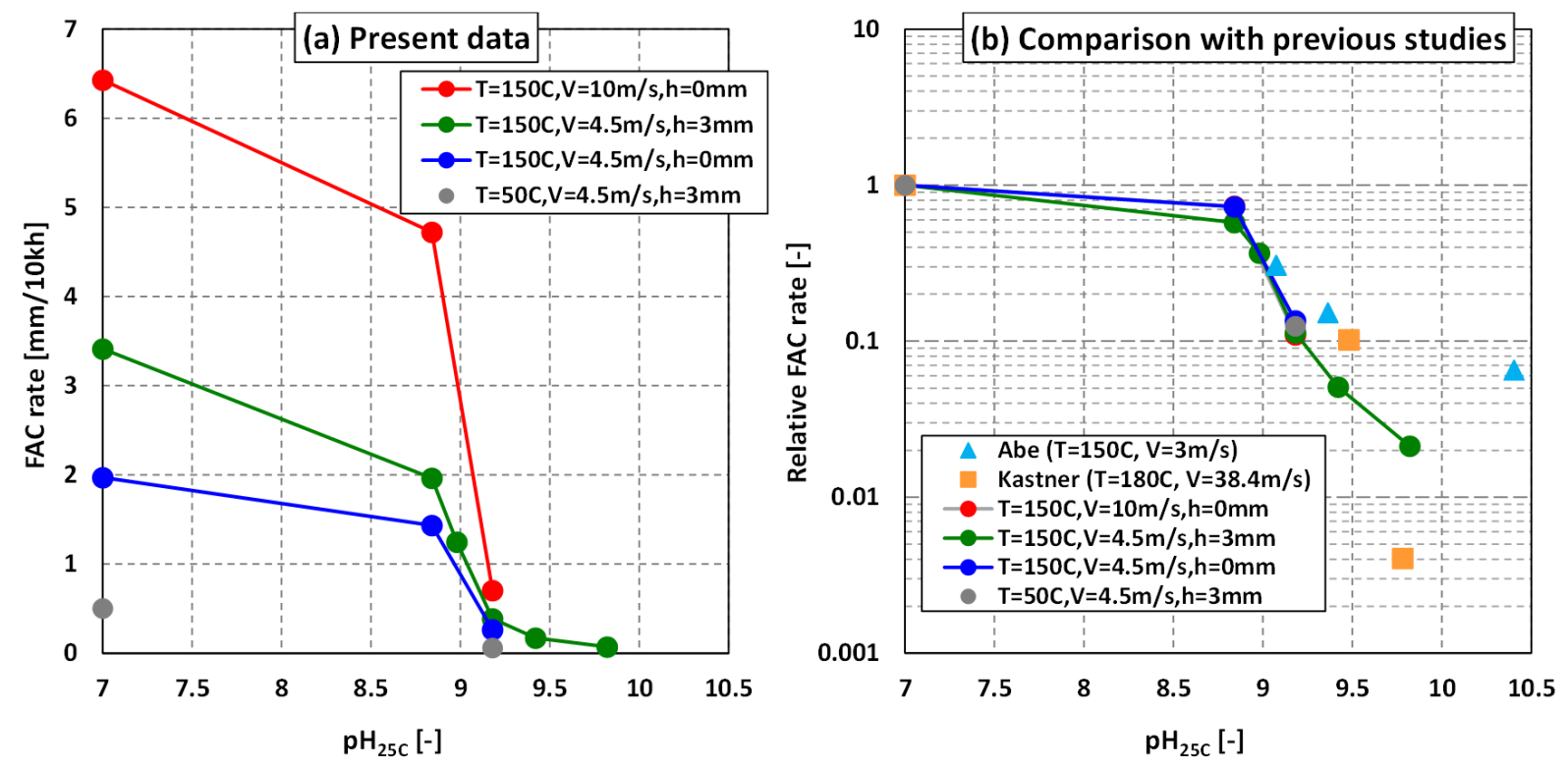

Fig. 11 Average FAC rate trend in terms of pH

According to previous studies, FAC rate is strongly related to iron solubility, and in some simple FAC model proposed, it is shown that FAC rate is proportional to iron solubility. Iron solubility trends for $\mathrm{pH} 7.0$ and $\mathrm{pH} 9.2$ are shown in Fig. 12 in terms of temperature (Fujiwara, 2011) calculated with hydrolysis constants of ferrous ions derived in previous study (Tremaine, 1980). When the temperature is $150^{\circ} \mathrm{C}$, the ratio of solubility between the two $\mathrm{pH}$ conditions is approximately $1 / 10$ while it is $1 / 30$ at $50{ }^{\circ} \mathrm{C}$. Hence, FAC rate difference between neutral $\mathrm{pH}$ and alkaline $\mathrm{pH}$ in the temperature at $150^{\circ} \mathrm{C}$ may be explained with the solubility, and for lower temperature condition, additional effect related to $\mathrm{pH}$ should be considered to evaluate the FAC rate.

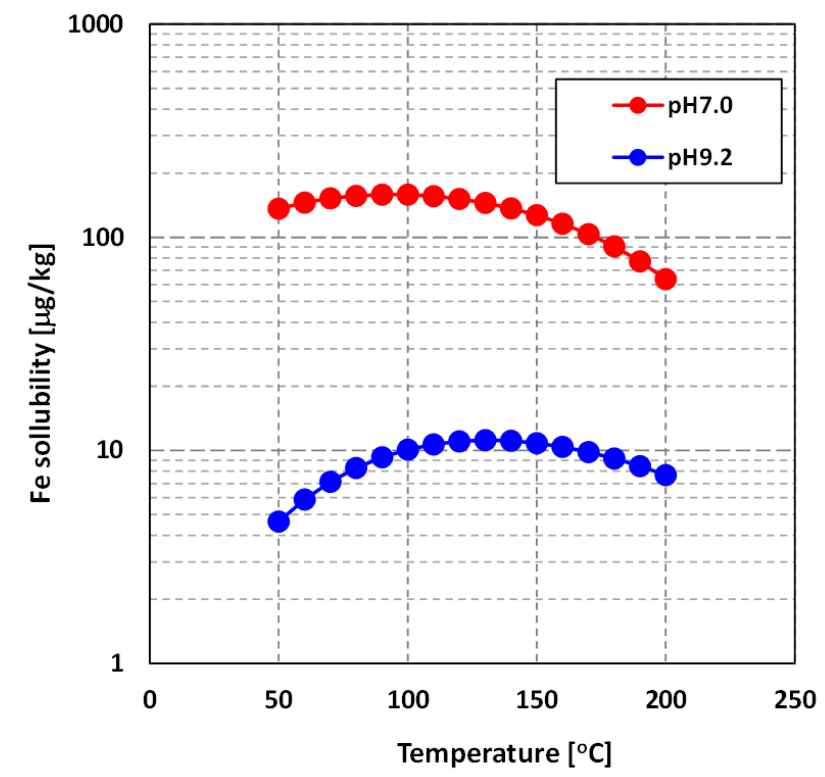

Fig. 12 Comparison of iron solubility between $\mathrm{pH} 7.0$ and 9.2

Present FAC rate data in terms of velocity is shown in Fig. 13. FAC rate is seen to increase monotonic with velocity, and it is proportional to the power of mean velocity with exponent from 1.0 to 1.5 , for cases with considerable FAC rate. This exponent for velocity dependency varies between previous data (Bignold, 1980, Heitmann, 1982) which may be influenced by the turbulence condition enhanced due to experimental geometry. 

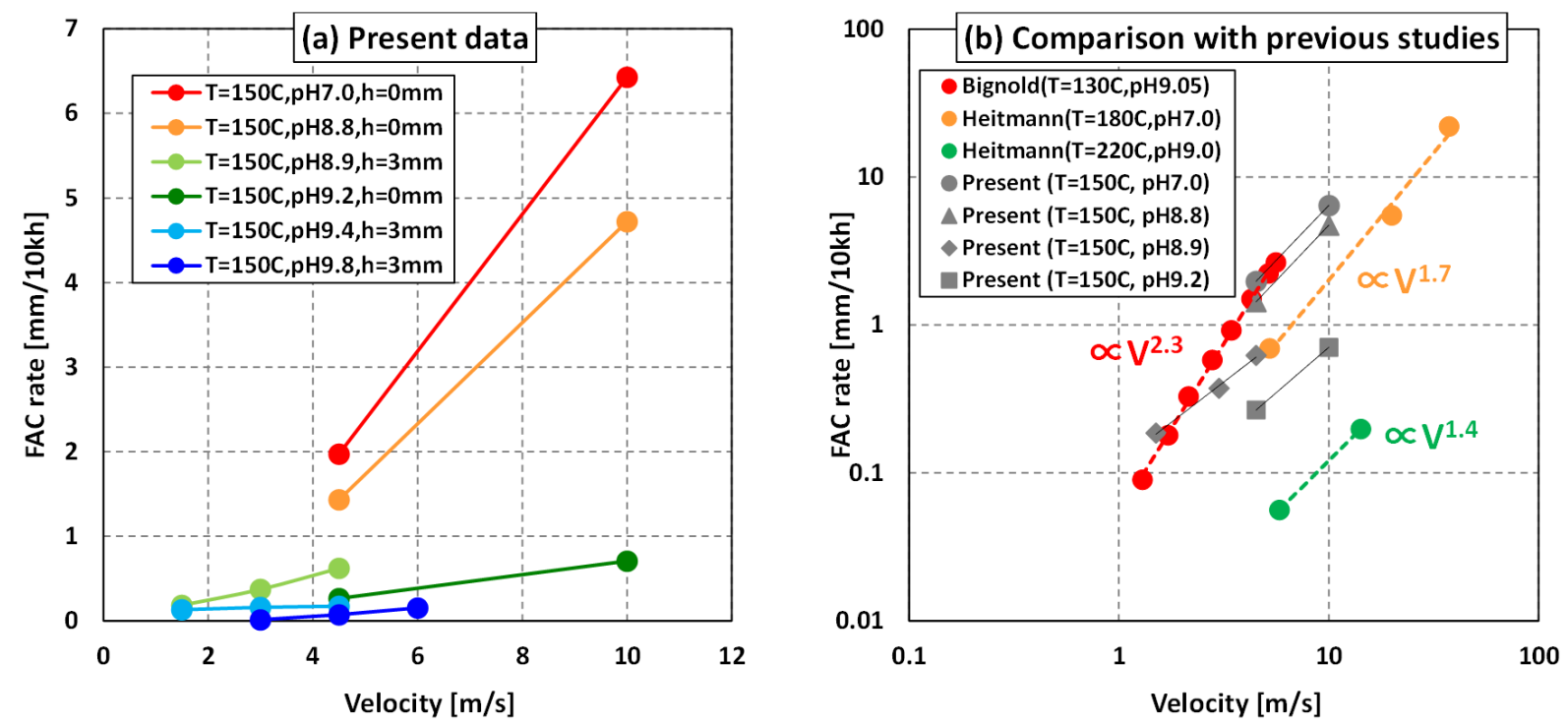

Fig. 13 Average FAC rate trend in terms of velocity

\subsection{Oxide film composition by XRD}

To identify oxide film composition formed on test specimen surface, analysis with X-ray diffraction (XRD) spectroscopy is conducted for representative specimens. $\mathrm{Fe}_{3} \mathrm{O}_{4}$ (magnetite), $\alpha-\mathrm{Fe}_{2} \mathrm{O}_{3}$ (hematite) and $\gamma$-FeOOH (Lepidocrocite) are set as the target composition of the oxide film. The results are shown in Fig. 14. In test condition with temperature of $150{ }^{\circ} \mathrm{C}$, magnetite is found in the oxide film, especially in high $\mathrm{pH}$ condition. For the low temperature condition of $50{ }^{\circ} \mathrm{C}$, very slight indication of magnetite is found in neutral $\mathrm{pH}$ condition, while none of the targeted compounds are detected in alkaline $\mathrm{pH}$ condition. There may be very thin oxide film formed below the detection level with the utilized equipment, which require to re-analyze in the future. As a whole, magnetite is only found in the oxide film on present test specimen surface which is one of the conditions that proves the occurrence of FAC. 


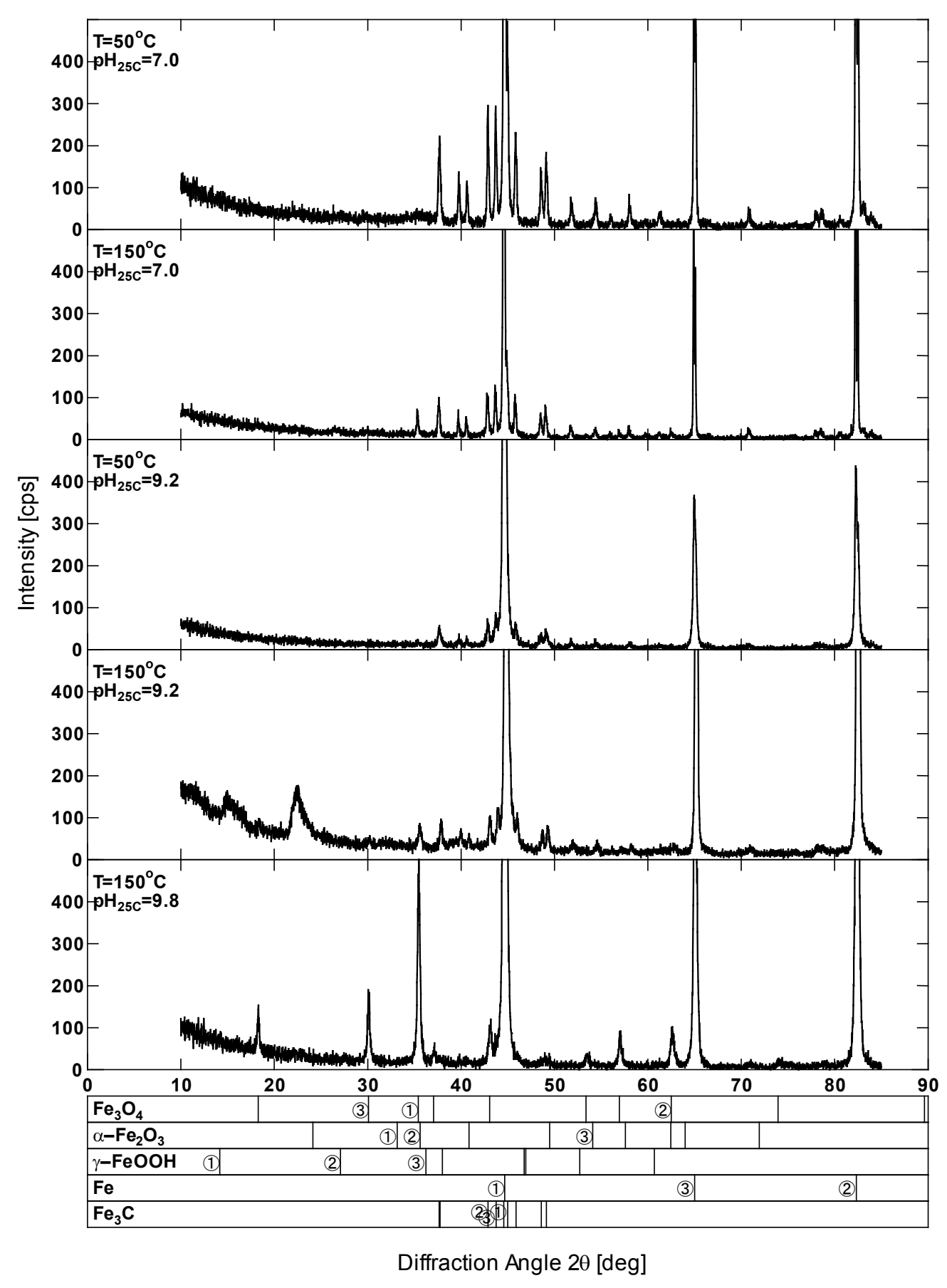

(1)(2): Angular position for the 1st, 2nd and 3rd characteristic spectrum for each iron compound)

Fig. 14 XRD analysis results for test specimen surface

\subsection{Iron concentration in the loop}

When FAC is simply modelled considering as a diffusion process of dissolved iron from oxide film surface to the bulk water by fluid induced mass transfer, Fick's law will be implemented. In this case, the driving force of diffusion will be the dissolved iron concentration difference between the oxide film surface and the bulk water. In this sense, when iron concentration in the bulk water is in saturation level, there would be no driving force which means no occurrence of FAC. This may also be adapted to a sophisticated FAC model such as Sanchez-Caldera's (1988).

The test loop used in the present study is not a once-through loop, and released iron originated from test specimen would increase and accumulate to a certain amount within the test duration time. However, the iron concentration will be balanced at a maximum value which is naturally determined as the ratio of dissolution rate from test specimens $M$ to the flow rate of the injection pump $q$. Total iron concentration in the upstream of the test section at a certain time $C(t)$ can be 
expressed, by adding the concentration in former time period and iron supply from the test specimens, which would be the concentration in the test section downstream, and subtract the extracted portion to the LP/LT loop, as Eq. (1).

$$
C(t)=\left[C(t-1)+\frac{M}{Q}\right]\left(1-\frac{q}{Q}\right)=\frac{M}{Q} \sum_{i=1}^{t}\left(1-\frac{q}{Q}\right)^{i}
$$

$Q$ is the flow rate of the circulation pump in the HP/HT loop. Dissolution rate $M$ is calculated by summarizing iron release from the exposed area of three test specimen surface by assuming constant FAC rate based on experimental results. With sufficient duration time, total iron concentration in the loop will eventually saturate as in Eq. (2).

$$
C(t) \rightarrow \frac{M}{Q}\left[1 /\left\{1-\left(1-\frac{q}{Q}\right)\right\}\right]=\frac{M}{q}
$$

This calculation is based on the assumption that total iron is dissolved, and in reality, some portion should be in nondissolved form. In that sense, the term "total iron contents" is applied instead of total iron concentration. It is also assumed that there is no dissolved iron supplied from the LP/LT loop, based on the measured results of conductivity in the pure water tank showing 0.06 to $0.08 \mu \mathrm{S} / \mathrm{cm}$, which is nearly in the pure water level and proving that most of the impurities are removed when passing through the ion exchange resin and filters.

In Fig. 15, the assumable maximum value of total iron contents for each test run is compared with saturation solubility of iron in each test run's temperature and $\mathrm{pH}$ condition. This figure shows that in about half of the test runs, total iron contents is nearly equal to or larger than saturation solubility. This would mean that the dissolved iron concentration of the loop water is nearly in saturation level, and iron compounds should also exist as flowing particles or deposits in the loop. However, as shown in Fig. 6, at least in neutral pH condition, thinning rate is confirmed to be constant during the test. For alkaline $\mathrm{pH}$ condition, although the thinning rate is not confirmed from in-situ measurement, FAC rate data are shown to present similar qualitative behavior with previous studies, which may be assumed to be valid. Hence, it is suggested that FAC may occur even when the iron concentration in the bulk water is in saturation level, which should be considered in the modelling process for FAC prediction.

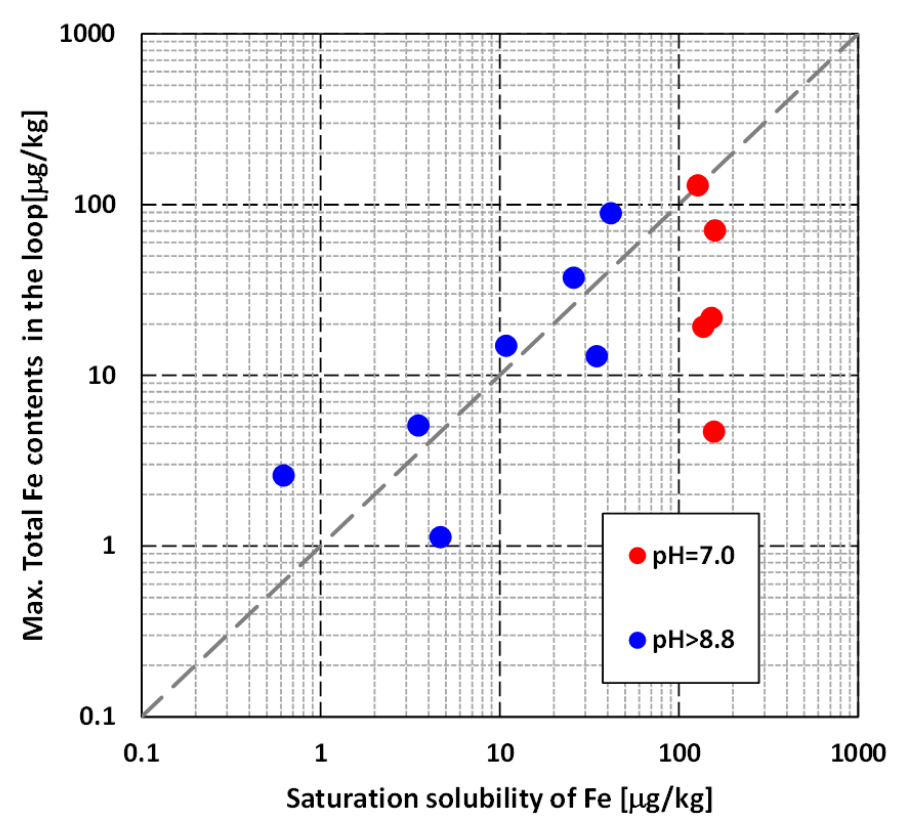

Fig. 15 Comparison of saturation solubility of iron with maximum iron contents in the test loop 
Although the reason for this results cannot be clearly explained, it may be hypothesized qualitatively by considering condition difference between the bulk and the specimen surface. At the specimen surface, hydrogen will be produced through oxidation process of iron in water, and hydrogen concentration would be relatively higher than that in the bulk. In general, iron solubility is in proportion to the one-third power of partial pressure of hydrogen (Sweeton, 1970, Tremaine, 1980). Accordingly, iron solubility at the specimen surface would be relatively higher than that in the bulk. In Fig. 14, saturation solubility is evaluated based on the bulk condition, however, actual solubility at the specimen surface may be higher which may relatively lower total iron contents than saturation level.

\section{Conclusions}

Experiments for FAC of carbon steel specimens were conducted and basic data were obtained. Especially, data in relatively low temperature condition down to $50{ }^{\circ} \mathrm{C}$ were acquired, which is scarcely found in previous studies although FAC susceptibility in low temperature pipelines are pointed out with care in plant management, recently.

In terms of temperature, $\mathrm{FAC}$ rate is seen to decrease by lowering temperature and the ratio of FAC rate at $50{ }^{\circ} \mathrm{C}$ to $150{ }^{\circ} \mathrm{C}$ is approximately $1 / 7$ to $1 / 6$, and the trend curve tends to remains to keep considerable level in lower temperature. FAC rate for $50{ }^{\circ} \mathrm{C}$ with $\mathrm{pH} 7.0$ is nearly the same or rather larger than that of $150{ }^{\circ} \mathrm{C}$ with $\mathrm{pH} 9.2$, which would mean that FAC susceptibility of pipeline in condensate demineralizer downstream and deaerator upstream in PWR plants is comparable.

In terms of $\mathrm{pH}$, a large drop in FAC rate is seen around $\mathrm{pH} 9.0$ as in previous studies, and its ratio at $\mathrm{pH} 9.2$ to $\mathrm{pH}$ 7.0 is approximately $1 / 10$. This is compared to iron solubility for its correlation with FAC rate, and when the temperature is $150{ }^{\circ} \mathrm{C}$, the ratio of solubility between the two $\mathrm{pH}$ conditions is approximately $1 / 10$ while it is $1 / 30$ at $50{ }^{\circ} \mathrm{C}$. Hence, FAC rate difference between neutral $\mathrm{pH}$ and alkaline $\mathrm{pH}$ in condition with $150{ }^{\circ} \mathrm{C}$ may be explained with the solubility, and for lower temperature condition, additional effect related to $\mathrm{pH}$ should be considered to evaluate the FAC rate.

Total iron contents in the test loop is compared with saturation solubility of iron to confirm its effect on FAC rate, and in about half of the test runs, total iron contents is nearly equal to or larger than saturation solubility, although FAC rate remained constant within the test duration. It is suggested that FAC may occur even when the iron concentration in the bulk water is in saturation level, which should be considered in the modelling process for FAC prediction. 


\section{Acknowledgements}

The authors are especially indebted to Mr. Shinya Morita for his devoted contribution in conducting the FAC experiments and test specimen analysis. The authors would also like to thank the members of Pipe Wall Thinning Working Group of FEPC (Federation of Electric Power Companies of Japan) for their continuous support for this study.

\section{References}

Abe, H., Ebara, S., Fujisawa, N., Hashizume, H., Sue, K., Watanabe, Y. and Yamagata, T., Understanding key parameters in flow accelerated corrosion for advanced wall thinning prediction, $4^{\text {th }}$ Int. Symposium on the Ageing Management \& Maintenance of Nuclear Power Plants, Tokyo, p.38-46 (2010).

Berge, P., Ducreux, J. and Saint-Paul, P., Effects of chemistry on corrosion-erosion of steels in water and wet steam, Water Chemistry II, BNES, Paper 2 (1980).

Bignold, G. J., Garbett, K., Garnsey, R. and Woolsey, I. S., Erosion-corrosion in nuclear steam generators, Water Chemistry II, BNES, Paper 1 (1980).

Chexal, B., Recommendations for an effective flow-accelerated corrosion program, EPRI NSAC-202L-R2 (1999).

Crockett, H. M. and Horowitz, J. S., Low temperature FAC, ASME PVP2009, 78029, Prague (2009).

Electric Power Research Institute (EPRI), Recommendations for and effective flow-accelerated corrosion program, NSAC-202L-R2 (1999).

Fujiwara, K., Doumae, M., Yoneda, K. and Inada, F., Effects of water chemistry and fluid dynamics on wall thinning behavior $<$ Part $2>$-Evaluation of influential factors by flow accelerated corrosion tests and prediction of corrosion potential-, CRIEPI Report, Q09028 (2010) (in Japanese).

Fujiwara, K., Doumae, M., Yoneda, K. and Inada, F., Model of physic-chemical effect on flow accelerated corrosion in power plant, Corrosion Science, 53, p.3526-3533 (2011).

Heitmann, V. H. G. and Kastner, W., Erosionkorrosion in wasser-dampfkreislaufen -ursachen und gegenmassnahmen -, VGB Kraftwerkstechnik, 62, Heft 3, p.211-219 (1982).

Horowitz, J. S., Flow-accelerated corrosion investigations of trace chromium, EPRI Report 1008047 (2003).

The Japan Society of Mechanical Engineers (JSME), Codes for Nuclear Power Generation Facilities - Rules on Pipe Wall Thinning Management for PWR Power Plants-, JSME S NG1-2006 (2006).

The Japan Society of Mechanical Engineers (JSME), Codes for Nuclear Power Generation Facilities -Rules on Pipe Wall Thinning Management for BWR Power Plants-, JSME S NH1-2006 (2006).

The Japan Society of Mechanical Engineers (JSME), Codes for Thermal Power Generation Facilities -Rules on Pipe Wall Thinning Management for Thermal Power Plants-, JSME S TB1-2006 (2006).

Kastner, W., Erve, M., Henzel, H. and Stellwag, B., Calculation code for erosion corrosion induced wall thinning in piping systems, Nuclear Engineering and Design, Vol.119, pp.431-438 (1990).

Keller, V. H., Erosionkorrosion an Nassdampfturbinen, VGB Kraftwerkstechnik, 54, Helft 5, pp.292-295 (1974).

Lister, D. H., Feight, A. D., Fujiwara, K., Khatibi, M., Liu, L., Ohira, T. and Uchida, S., The mitigation of flowaccelerated corrosion in the feedwater systems of nuclear reactors - the influence of dissolved oxygen under different operating conditions, Power Plant Chemistry, Vol. 13, No. 4, pp.188-196 (2011).

Makino, S., Iwamoto, K. and Kawamura, H., DNS of turbulent channel flow with an orifice, Proc. Annual Meeting of Japan Society of Fluid Mechanics (JSFM), AM06-22-002 (2006) (in Japanese).

Nuclear and Industrial Safety Agency (NISA) / Ministry of Economy Trade and Industry(METI), Automatic Shutdown of Mihama Power Station, Unit-3, Kansai Electric Power Company, Press Release Information (2004).

Sanchez-Caldera, L. E., Griffith, P. and Rabinowicz, E., The mechanism of corrosion-erosion in steam extraction lines of power stations, Trans. ASME, Vol. 110, p.180-184 (1988).

Sweeton, F. H. and Baes, Jr. C. F., The solubility of magnetite and hydrolysis of ferrous ion in aqueous solutions at elevated temperatures, J. Chemical Thermodynamics, Vol. 2, pp.479-500 (1970).

Tomarov, G. V., Shipkov, A. A., "Simulation of physicochemical processes of erosion-corrosion of metals in two-phase flows," Thermal Engineering, Vol.49, No. 7 pp.530-540 (2002).

Tremaine, P. R., LeBlanc, J. C., The solubility of magnetite and the hydrolysis and oxidation of $\mathrm{Fe}^{2+}$ in water to $300{ }^{\circ} \mathrm{C}$, J. Solution Chemistry, Vol. 9, No. 6, pp.415-442 (1980). 
Trevin, S., EDF knowledge of flow-assisted corrosion in PWR type NPP, EDF Report, ENTECH050089 (2005).

Tsuruta, T., Murata, K., Shoda, Y. and Yamamoto, K., Flow accelerated corrosion study using rotating disk specimen, Proc. Fontevraud 6, Vol. 1, Session A., p.181-190, SFEN (2006).

United States Nuclear Regulatory Commission (U.S.NRC), Feedwater line break, Information Notice No. 86-106 (1986).

Utanohara, Y., Nagaya, Y., Nakamura, A. and Murase, M., Influence of local flow field on flow accelerated corrosion downstream from an orifice, J. Power and Energy Systems (JSME), Vol. 6, No. 1, pp.18-33 (2012).

Utanohara, Y., Nagaya, Y., Nakamura, A., Murase, M. and Kamahori, K., Correlation between flow accelerated corrosion and wall shear stress downstream from an orifice, J. Power and Energy Systems (JSME), Vol. 7, No. 3, pp.138-147 (2013).

Yamakami, K., Hirano, S. and Nakamura, T., Analysis of data on pipe wall thinning phenomena by fluid flow in pressurized water reactor plant, Transaction JSME, B 74, 745, pp.4-13 (2008) (in Japanese).

Yoneda, K., Ohira, T., Tanji, K., Akiba, S., Niiyama, K., Inada, F. and Morita, R, Evaluation of hydraulic factors affecting flow accelerated corrosion and its verification with power plant data, ASME PVP2009, 77486, Prague (2009).

Zander, A. and Nopper, H., COMSY software assists lifetime management activities, Transactions of SMiRT 17, Prague, D05-5 (2003). 